\title{
Historein
}

Vol 1 (1999)

\section{History and Semiotics}

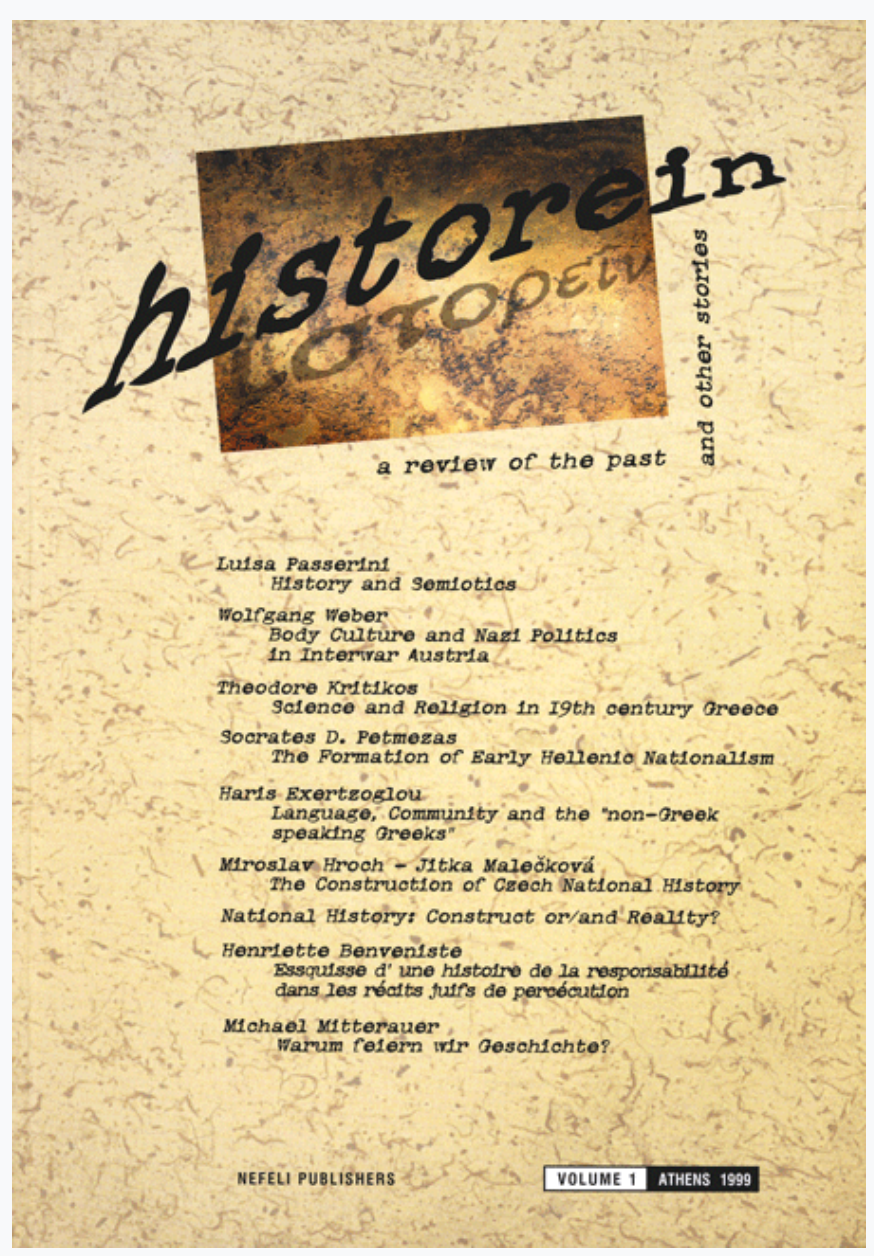

\section{Bulletin}

Historein Historein

doi: $10.12681 /$ historein.134

Copyright $\odot$ 2012, Historein Historein

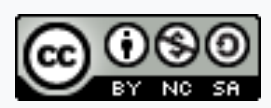

This work is licensed under a Creative Commons Attribution-NonCommercialShareAlike 4.0.

\section{To cite this article:}

Historein, H. (2000). Bulletin. Historein, 1, 201-210. https://doi.org/10.12681/historein.134 


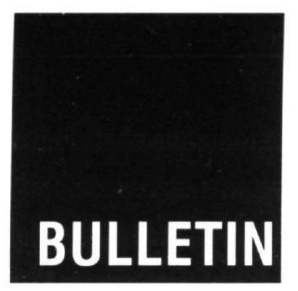

is a special section devoted to short announcements about conferences, workshops, seminars, and meetings that take place in Greece or elsewhere and represent the current state of activities in the particular field of historical studies that Historein seeks to promote. Historein encourages readers to notify the editorial board about events that will have taken place during the academic year 1998-99.

\section{Conference Survey}

\section{by Vangelis Kechriotis}

It seems reasonable to suggest that the issues of conferences reflect the interests of the academic community in any given country, or sometimes the views and needs of the society itself. If this is true, it's worth giving an outline of the major events of the past two years concerning historiographical research in Greece. It goes without saying that we will come across issues which emerge not only as historiographical problems but also sometimes as questions about actual social activity. In that sense, Conferences about the ideological use of ancient legacy, the first prime minister who undertook a modernisation program, the thirty years since the 1967 coup d' etat, modern Turkey and Islam, and an exile island during the civil war, provided opportunities for discussion on questions of broader interest. On the other hand, there have been new approaches in historiography that in recent years have developed within the Greek academic community. Oral history, urban space in modern times, the history of childhood, history and theory, history and microhistory, the study of poverty, themselves constituted issues which instigated interesting methodological discussions.

\section{The boundaries of ancient legacy Rethymno, November 1996}

The diverse reception of ancient culture in modern Greek society was the issue of a conference held by the University of Crete. Most of the sessions concerned the symbolic dimensions of the representation of this heritage, including traits in literature, in language and education, on the scene and screen. Central to the debates were the stereotypes created especially in and through European literature, the myth-making about ancient times and the ways the created myths affected Greek culture. The Greek state, since its creation, has largely grounded its existence on the ideological preconception that it was the only legitimate inheritor of ancient Greek culture. Although this heritage had to reconcile with the Christian Orthodox character of post-Ottoman culture, it had been necessary for modern Greeks to correspond to the narrative Europeans had created about their origins. Consequently, even if there have been diverse options about the structure of modern-Greek identity, the predominance of ancient Greek culture has been in no doubt. This persistence through time has created a huge literature and has greatly affected institutional development. The study of this process is valuable in deconstructing modern Greek identity. Another important element in a great number of papers was the interdisciplinary character of approaches. It is a perspective newly appropriated by Greek historians but already fruitfully incorporated in their research. The paths through which epistemology, geography, semiotics, intellectual history, and social 
anthropology coexist and contribute to more elaborate conceptions of the past were indicated, though not thoroughly demonstrated in this conference. It is also worth mentioning that the reconsideration of an issue so central to modern Greek culture has given rise to new historiographical fields such as theater, cinema, sports, which must also be further elaborated.

\section{Harilaos Trikoupis and his era Athens, November 1996}

On the occasion of the centennial of the death of the outstanding Greek politician of the 19th c., Harilaos Trikoupis, a conference was held by Panteio University. Trikoupis was the instigator of a modernisation project for the Greek state during his dominance on the political scene (18751893). Until that time, both the social structures and the state apparatus had not seemingly differentiated themselves from the Ottoman past. Yet, the push for the creation of a modern Western-like national state had always been at stake for all social and political powers. Since there also had been the demand for the expansion of the Greek body-politic to include Greek populations of the Ottoman empire through a policy called the "Great Idea", Trikoupis suggested that it was wiser first to improve the social, financial, and political conditions of the state itself. A conference for Trikoupis has come just in time since it is important to reconsider the whole modernisation movement which then took place. Moreover, a powerful political debate has developed during the last few years about the need for a new modernisation project which will affect every aspect of Greek society from finance to education. It is obvious that this new project responds to a different time, in a completely different context, namely the participation of Greece in the European Union. Yet, perhaps it would be useful to bear in mind the insufficiency or the discontinuities of Trikoupis' policy which, even if it had a beneficial impact on Greek society in the long run, resulted, in 1893, in economic and, consequently, social bankruptcy. It is reasonable to expect from a conference like this to make the bridge between times and projects and produce a dialectical discourse which will shed light on the past as well as the present and future of Greek society. The subject matters discussed during the sessions covered a range which included internal policy and diplomatic relations, public finance and administration, ideology and social conflicts, education, literature and intellectual history. Nevertheless, the historical approach to the subject, with few exceptions, seemed to neglect the broader structural dilemmas which seem to confirm themselves even today, or persistently elide any connotation of the past with the present in order to safeguard the so-called "autonomy" of historiographical research.

\section{Islam and modern Turkey Athens, December 1996}

The development of the Islamic movement in modern Turkey was discussed by three Turkish historians who were invited by the University of Athens. Ilhan Tekeli presented the role of the Islamic past in modern Turkey and focused on different approaches to Islam, from the Tanzimat era until today, in Turkish society. Binnaz Toprak discussed the role and place of women in modern Turkey as a result of the impact of the Islamic tradition. She argued about the deep difference between the two main groups in Turkey, Islamists and the Kemalists, in facing women. Finally Ismet Ozel's contribution concerned the relations between the state and the Islamic community, and he argued for the political separation of religion and state. The meeting was important since the recent development of Islamic movement in Turkey as well as in countries such as Egypt and Algeria has been a landmark in the 
formation of new identities in these countries. Maria Efthymiou, a Greek historian who instigated and was responsible for organizing this meeting, conducted the discussion which, unfortunately, focused on the pathology of Turkish politics, especially on issues of external policy, and not social and cultural issues. Nevertheless, it was interesting that the speakers' reaction to that emphasis was to declare that the European orientation of Turkey is an undeniable fact and that the current rise of Islamic fundamentalism in Turkey is a relatively marginal phenomenon.

\section{The temporalities of history concerning the history of childhood and youth}

\section{Athens, April 1997}

The recent historiographical categories of childhood and youth were the issue of a conference held by the Historical Archives of Greek Youth (HAGY) in collaboration with the Center for Neohellenic Research of the National Research Foundation (C.N.R./N.R.F.). The HAGY was created by the General Secretariat of Youth at the Ministry of Culture fifteen years ago and has largely encouraged research of youth and childhood by funding young historians. As the delegate of the academic board of HAGY, the historian Triantafyllos Sklavenitis has put it: "the expectation of the conference had been to introduce a variety of approaches primarily concerning different aspects of time in history, in terms of educational mechanisms, labor relations, anthropology and mentalities, politics, art, leisure and sports." The diversity of sessions fulfilled this goal and contributed to the emergence of new historiographical views. If we compare this second conference to the first one which was held in 1984 under the title /Historicity of childhood and youth?, we can make two important points. First, the recent conference demonstrated the tensions which have been already mentioned about Greek historiography (multiplicity of approaches, appointment of wholly new interests), whereas in the first conference there was an overwhelming predominance of history of ideas and educational mechanisms. The second issue concerns the international character of the first conference, unlike the recent one where most of the participants were Greek. This change can be attributed to the fact that there have been so many young Greek researchers who have been encouraged through funding not only by HAGY but also by other institutions which have intensified their activity during the last fifteen years. Fourteen projects concerning the history of youth were financed in 1996, and in order to promote research activity a series of thirteen seminar meetings was organised at CNR, which has given official hospitality to HAGY activities.

\section{Rich and poor in the Latin East Athens, May 1997}

The question of poverty was the major issue in the conference on the Latin East held by the University of Athens. Historian Chrysa Maltezou, chair of the conference's organizing committee, described the main interests of the meeting: the exploration of social phenomena through the contradiction wealth-poverty in the regions of the Latin East; the study of the development of the terms "povero", "miserio"; the difference in wealth between the metropolitan city and the colonies; and the study of ethnic self-image within current discussions about nationalism. This variety of issues is interesting for social history and the study of "microhistory". Yet many of the conference papers tended to be descriptive and did not attempt to question the use of the terms, especially "poor"-"rich", or to translate the context in modern terms. 
Testimonies in sound and image as a source for history

\section{Athens, May 1997}

The first meeting on oral history was held by the University of Athens. Obviously, it was of great importance in epistemological terms. Yet, in terms of methodology there was a diversity of older and modern approaches. During the first session, historians from different countries discussed their national experience. Mercedes Villanova, Robert Perks and Franco Castelli contributed a great deal to a broad discussion focused both on the rejection of the mainstream historical attitude which ghettoizes oral history as well as on the systematic and usable arrangement of oral documents. The discussion was conducted by the historian Aleka Boutzouvi, who was responsible for organizing this meeting. She also brought in the Greek experience. Afterwards, Greek historians and journalists had the chance to present diverse aspects of the Greek past and present in oral testimonies. During the second session, the emphasis was on archives of the cultural inheritance of the Greek population outside Greece, namely Cyprus and Asia Minor. The third session concerned the legal and financial circumstances for the formation of a usable corpus in order to take advantage of the very rich historical archives of Greek broadcast and television. Since this was the first meeting for oral history held in Greece, it was valuable for creating a fruitful forum.

\section{Theory and History: a coexistence Ermoupolis, July 1997}

Every year, in Ermoupolis, the capital of the Cyclades, a series of seminars is organised by the Center for Neohellenic Research of the National Research Foundation in collaboration with the Cultural Foundation of Cyclades. Last July, a debate took place concerning the status of theory in various disciplines. The meeting considered theory from historical, epistemological and philosophical points of view. We will refer to the first section. The seminar developed the major theme of the ability of history to produce theory. There was an interesting discussion about the place of history among social sciences. The central question was if historiographical discourse only provides the facts which will be elaborated later on by other disciplines. It was argued by members of other disciplines that there is a contradiction between "statements" and "narratives". While history can deal with statements, which can be verified, it cannot create narratives since there is no way to prove "scientifically" their accuracy. Consequently, the issue for some people was the restriction of history to a verification role. The responsibility for creation of schemes and narratives was thus attributed to philosophy or sociology. It is obvious that such an approach refers to an extremely traditional categorization of disciplines and the illusion that pure knowledge can exist. It is greatly accepted within social sciences that any kind of presentation includes a hermeneutic approach. The historian always produces theory through her work.

\section{Urban space in modern time.}

\section{Mediterranean and Balkan aspects} (19th-20th c.)

\section{Athens, November 1997}

The construction of urban space was the issue of a conference organised by the Society for the Study of the Modern Greek World which publishes the review Mmemon. It was the second conference on urban space organised by the society. The first was in 1984, when the focus was on the modern Greek city and its origins in the Ottoman past. This second meeting aimed at describing the field of research fifteen years later. There were some interesting points. The first concerned the apparent persistence, to some 
researchers, of the unique character of the modern Greek city. The very title of the conference presupposed that there is no such thing, and that it's important to consider the Mediterranean or Balkan traits in an account of any urban space of the area. This different focus in relation to the first meeting was present in a lot of papers. Another point concerned the remark that during the last years, there has been a fragmenting of social history. This suggestion was ascribed to the general questioning of the importance of social structures in human activity following political changes of 1989. Nevertheless, what proved to be fruitful now more than in the past was the collaboration among different disciplines - history, architecture, literature, anthropology, even cyberspace - which led to very stimulating approaches. This became apparent in the sessions which concerned not only social relations and demographic changes, but also new needs and phenomena, the memory of the city, the representation of urban space, and the city in literature.

\section{Dictatorship, regime-origins- influences, 30 years later Athens, December 1997}

1997 was the thirtieth anniversary of the imposition of military rule in Greece, which lasted for seven years. The ruling junta of the period was the final political outcome of the post-civil war social conflict between right and left which so deeply influenced Greek society. The Greek Society of Political Science held a conference to examine the impact of the junta on almost every domain of social life from institutions and labor relations to press and mass media. Another key issue was the role of the army and the antidictatorial struggle here and abroad. Yet, the really important question of the conference was to examine how things led to such an unhappy development. For instance, there was already a longstanding debate about the role of external factors, such as the intervention of the U.S. Even if U.S. officials were not really informed about the coup and were taken by surprise, as it has been suggested, it was the Cold War atmosphere, mainly inspired by Americans, which had created in Greece the structures of violence which for twenty years had their own logic and actually led to a state within a state in Greece. As a matter of fact, even if there was no political intention, there is a strong moral responsibility not only on the part of external actors but also on the internal factors which created a monster with a life of its own. Nevertheless, it's worth mentioning that thirty years later, even if some wounds are still open in social life, younger people seem to ignore, and older ones to neglect, this important period. Memory hasn't seemed to make the bridge yet.

\section{Microhistory and history: supplementary or contradictory fields?}

\section{Athens, February 1998}

The relation between history and anthropology was discussed in a meeting which concerned the importance of microhistory for historiographical research and was held tyy the society of a private school called Moraitis. Examples from different periods aimed to illustrate this relation. From book production and literacy to the travels of Jews and their image of space, from the activities of a family to theoretical accounts about local knowledge in relation to the past and Ginzburg's contribution. Central to the relation between history and anthropology have been the questions of whether microhistory is useful and why in Greece there has been a delay in the development of microhistorical studies. It was argued that in order to deal with these questions one must allow microhistory some degree of disciplinary autonomy. Thus, it was argued that it's not 
necessary to consider a discipline through its usefulness to other ones. Besides, the emergence of a research field in a national historiography can follow developments abroad, yet it should also respond to internal needs. Therefore, it is important for an approach which tries to incorporate a method to avoid a superficial application. In any case, collaboration between history and anthropology should not submit one to the other, since the attempt to certify the hegemony of a discipline can only lead to misuse of the other.

\section{Historical place and historical memory: the example of Makronisos Athens, March 1998}

Very recently, strong historiographical interest has concentrated on the Greek Civil War of 194649 and the post-civil war era. One of the most privileged subfields in this burgeoning area of historical interest are the exile islands, where Greek communists were banished for years following the end of the war. The meeting about Makronisos, an island where thousands of left wing people conducted their military service, in an atmosphere of torture, was associated with a project for the historical protection and development of the physical site of Makronisos. The central assumption was that this protection would work to rescue the historical memory associated with the place. It was also an attempt to define the field of research through reference to foreign archives, the place of Makronisos in literature, the structure of the camp, and the experience of torture. Contributions to the meeting were exclusively by researchers, which meant that there was a lack of personal testimony. Yet, it became obvious that popular memory has largely put boundaries on the study of this time and place. The recent development of this research has had to overcome these boundaries and thus to differentiate itself from popular memory, yet not entirely contradict it. What emerged from the meeting was the question of how to treat memory in order not to cancel it but to enrich it through archival research.

\section{Graduate seminar \\ Rethymno, July 1996}

The initiatives taken by the History Department in Crete include the graduate seminars organised each summer over the past three years. In the 1996 seminar, graduate students from Crete, Athens, Thessaloniki and abroad took part. Discussions focused on methodology and the theoretical elaboration of the research proposals and preliminary findings of the work of young researchers from the whole spectrum of social sciences. It is obvious that this event has obtained a broad character and has become unofficially the annual meeting of history graduate students in Greece.

This report on recent conference activity should be concluded by a short reference to societies which have parallel activity. The Society for the Study of Modern Greek World which publishes the review Mnemon, holds an annual workshop during which mainly young researchers from all the social science fields present and discuss their work. We have already mentioned the activity by the Historical Archive of Greek Youth. One should also note the lectures organised by the Anthropological Society and the Greek Society of Political Science? which publishes the Greek Survey of Political Science. The ongoing activities of these groups contribute to the development of disciplinary discourse in each case as well as the promotion of interdisciplinary dialogue.

Heterodoxies: construction of identities and otherness in medieval and early modern Europe Syros, July 20-21 1998

This conference was organised by Costas 
Gaganakis and Rika Benveviste in the context of the annual Seminars of Ermoupolis, Syros. A great number of scholars in the field of early modern European history presented original papers on different aspects of the process of formation of European identities. Participants included: Ch. Angelidi (National Institute of Research, Athens), H. Asséo (Centre d' Etudes Tsiganes, Université Paris V), R. Benveniste (University of the Aegean), C.F. Black (University of Glasgow), Th. Dantelet (Princeton University), N.Z. Davis (Princeton University, University of Toronto), M. Euthymiou (University of Athens), C. Gaganakis (University of Athens), C. Ginzburg (University of Bologna), T. Kioussopoulou (University of Crete), P. Kitromilides (University of Athens), A. Liakos (University of Athens), A. Molho (Brown University), V. Panagiotopoulos (National Institute of Research, Athens), G. Ricci (University of Ferrara), S. Woolf (European University Institute, Florence). The conference was widely attended by Greek historians and graduate students and the originality of the papers stirred vivid discussion around central issues of the early modern European history as well as cultural history in general.

\section{Memory and History Athens, June 1997}

by Ageliki Koufou

A two day meeting organised by the Cultural and Intellectual History Society (CIHIS) was held in Athens in June 1997. The meeting explored the relationship of history and memory through three sessions devoted to the subjects of "Conceptions of Memory", "Places of Memory" and "History in the First Person". A fourth session was devoted to discussing the relationship of psychoanalysis to history.

In the first session E. Gazi and A. Koufou discussed the evolution and modifications of the concept of memory in the Western tradition from mnemonics to counter-memory. E. Gazi argued that the art of mnemonics was not simply a memorising technique but a theory of knowing and interpreting the world which associated memory to knowledge. A. Koufou examined the origins of counter-memory and its role in undermining traditional concepts of historical knowledge. The paper presented Foucault's emphasis on discontinuities and ruptures which led him to challenge the canonical evolution in history, and sciences in general, and adopt a different conceptualisation which disrupts the relationship of history with memory as a homogeneous and linear unity. D. Kavoura argued that stored knowledge and memory (feelings, experiences, etc.) are used as mental tools of understanding historical events creating a continuity which corresponds to biological time. This process identifies social memory and memory-knowledge as two aspects of the same (cognitive) identity. A. Liakos foregrounded the 
significance of oblivion as a presupposition of history. Oblivion functions selectively in the formation of memory, as "an organised amnesia or amnesty" which contributes to [political] stability. History as hermeneutics is also based on oblivion in its inability to reconstitute the past as a whole.

The second session surveyed space and places as organising fields of memory. A. Chaniotis examined the construction of collective memory in the Hellenistic town. Using Greek inscriptions and passages from Plutarchus, he insisted that keywords not only formulated but dissolved collective memory and accentuated the role of religious sites in forging national memory. C. Gaganakis discussed the role of memory in the formation of the Protestant identity arguing that Protestantism used the press par excellence in order to forge a distinctly anti-Catholic religious identity. In this effort Protestants foregrounded French identity, juxtaposing it to Italian Catholicism, and developed a circular conception of time against the linear time established by the Catholics. A. Tzortzakis and I. Pentazou dealt with the role of the museum as locus of memory. A. Tzortzakis approached the evolution of museums through history focusing on the different conceptions which corresponded to different socio-cultural contexts. I. Pentazou analyzed the first exhibition of national souvenirs in modern Greece in 1884, and juxtaposed memory to reality by showing the permeability of the limits between past and present. This exhibition can also be seen as an attempt to manipulate living memory by constructing the representation of the Greek Revolution in a selective way.

The third session was devoted to oral memory and autobiographies. A. Bountzouvi touched upon issues regarding oral memory, treating it as a form of memory in its own right, distinct from the written forms of 'memory. Focusing on oral tradition she also distinguished two streams in oral history corresponding to two different concepts of memory: the Freudian (memoryreservoir) and the active memory. The paper brought attention to the political dimension in the analysis of oral memory and the way it fashioned the diversity of individual identities. $P$. Handzaroula compared the autobiographies of $D$. Frazer and C. Steedman and examined the ways the personal and the collective are interwoven in the field of memory. As she claims, both Frazer and Steedman saw individual history as the site (locus) where other people's history is reflected and where social and political components converge. P. Voglis presented a similar view in his paper, which surveyed the memoirs of political prisoners in Greece. Voglis compared the autobiographies of political prisoners to traditional forms of autobiographies which follow the rules of bildungsroman and concluded that in the former the individual is subsumed in the collective as the "insignificant" individual experience is refracted through the collective experience.

In the fourth session $\mathrm{H}$. Karamanolakis attempted a psychoanalytical approach to memory, which A. Liakos commented upon, investigating the relationship between history and psychoanalysis. Underlining the healing role of memory in psychoanalysis, Karamanolakis argued that the emergence of repelled memory provoked by trauma leads to the rehabilitation of the patient but insisted that although re-emerged memory can be an invented one, its importance in individual personality should not be diminished. In this process oblivion also plays an important role, as it is sometimes necessary to remember in order to forget. Liakos discussed the relation of history to psychoanalysis and their similarities by comparing the structure of the dream to the structure of historiography. Although he juxtaposed the factual dimension of history to the interpretative dimension of psychoanalysis he 
pointed out that both historians and analysts reach knowledge through the fractures of narration. Yet, in spite of its contribution to intellectual history, psychoanalysis cannot be properly applied to history because of its lack of historicity and its solid emphasis on interpretation instead of truth.

\section{Internationales} Forschungszentrum Kulturwissenschaften Institut für Geschichte, Abteilung für Südosteuropäische Geschichte, Graz "Migration im Interdisziplinären und Internationlen Kontext" Vienna, 3-8 June 1997

\section{by K. Papakonstantinou \&}

I. Laliotou

Scholarly discussions over issues related to migration have acquired a particular importance in the contemporary political context. The contemporary phenomenon of migrations in the Balkans has created political and social conditions that force us to re-consider the history of the area as multiple histories of migration.

This perspective formed the interests and themes that were discussed in the international conference on "Migration im Interdisziplinären und Internationlen Kontext" that took place in
Vienna in June, 1997. The conference was coorganised by professor Michael Mitterauer, University of Vienna and professor Karl Kazer, University of Graz. Participants were invited from different countries in the Balkans, but also from Western Europe and the United States.

The theme of migration was approached from an interdisciplinary perspective with emphasis on history, sociology, ethnography and anthropology. The participants' commitment to interdisciplinarity and the broad range of cases that were presented resulted in the formation of an interesting and challenging forum of scholarly exchange. Presentations covered a broad chronological as well as geographical range, as participants discussed cases of migration from the Balkans and Italy to Central Europe, Germany and the United States. Other presentations discussed the cases of asylum seekers and different types of temporary migration such as the migration of students from the Balkans towards Vienna.

Provocative discussion developed around methodological issues that concerned the difficulties that arise from the great variety of types of migration and migrants (i.e. asylum seekers, labor migrants, students, enterpreneurs) and the critique of particular concepts that have haunted migration studies and become problematic in contemporary approaches (i.e. the concepts of acculturation, integration, assimilation). Discussions over sources and the use of testimonies and autobiographies in historical research indicated an active interest in the issues of subjectivity and experience in the study of migration.

One of the main objectives of this conference was related to historical research on migration with the contemporary political and social dimensions of the phenomenon. Thus the last day accommodated an encounter among the 
participants and social workers who work with Turkish migrants in Vienna. This encounter led to fruitful exchanges of experience and knowledge and approaches between social scientists and social workers. The exchange however also revealed the fact that although social research and analysis has made decisive steps towards the study of national histories of the Balkans as histories of multiple migration, social policy and politics in the countries that receive migrants are still trapped in notions which view both migration as a social problem imposed by the migrants onto the recipient society and migrant life as a pathological form of social existence. Historical and interdisciplinary study of migration in international perspective has the potential to illustrate the ways in which processes of nationbuilding have always been accompanied by phenomena of movement of populations. National cultures have been historically formed through processes of migration of people, ideas, technology and knowledge. This conference indicated that social policy in the recipient countries could still benefit from the adoption of such a historical perspective. This benefit would consist in the realisation of the ways in which migrants do not constitute a problem for the recipient countries, although in certain cases migration creates the conditions for pre-existent elements of xenophobia, racism and exclusionism to become culturally prominent. This conference provided a valuable forum that allowed the urgent need for closer exchange between social scientists and social workers on the one hand, and social science and social policy on the other, to emerge. 